\title{
Association between Interpersonal Social Support and Perceived Depression among Undergraduate College Students of Kolkata during Unlock Phase of COVID-19 Lockdown
}

Dr. Rituparna Basak ${ }^{1}$ and Debashree Sinha ${ }^{2 *}$

'Assistant Professor, Department of Psychology, Muralidhar Girls' College, P411, 14, Gariahat Road, Golpark, Hindustan Park,
Ballygunge, Kolkata India
${ }^{2}$ Lecturer, Department of Psychology, Surendranath College, 24/2, Mahatma Gandhi Road, Kolkata-700009, India

\author{
Article History \\ Received: 08.12 .2020 \\ Accepted: 24.12 .2020 \\ Published: 30.12 .2020 \\ Journal homepage: \\ https://www.easpublisher.com
}

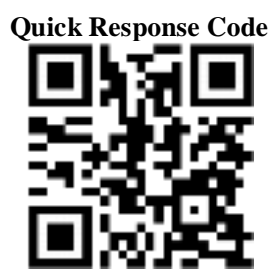
perceived depression among under graduate college students of Kolkata during unlock phase of covid-19 lockdown. Two random samples of 200 participants ( 100 males \& 100 females) aged 18 to 20 years residing in Kolkata were selected. The Beck Depression Inventory - Second Edition (BDI-II) and Interpersonal Support Evaluation List (shortened version) along with a general information schedule were administered on selected samples through online. Findings suggest that the as female college students scored higher in depression than male students and in case of social support female college students scored comparatively less than male students during unlock phase II for Covid-19 pandemic. Social support can be considered to be protective force against depression and there was a negative spiral between social support and depression. Results also confirmed that students are less depressed when they get more social support and especially the tangible support. Persons with strong social support are better able to cope with stressors, whereas those with less support may be more vulnerable to the adverse effects of stress, such as depression.

Keywords: Interpersonal Social Support, Perceived Depression and unlock phase.

Copyright $(\mathcal{2 0 2 0}$ The Author(s): This is an open-access article distributed under the terms of the Creative Commons Attribution 4.0 International License (CC BY-NC 4.0) which permits unrestricted use, distribution, and reproduction in any medium for non-commercial use provided the original author and source are credited.

\section{INTRODUCTION}

Originating as a cluster of unexplained cases of pneumonia in Wuhan, China, novel coronavirus disease - officially designated as COVID-19 by the World Health Organization - has reached the level of a pandemic, affecting countries all across the world. With the world battling one of the biggest health emergencies in recent times, the coronavirus has brought with it a mental health pandemic as well. The uncertainty of the lockdowns across the world along with the fear and anxiety of the disease has taken a toll on mental health of a greater number of people. As a life threatening disease, we can consider COVID-19 outbreak as a specific stress. Psychosocial responses towards infectious disease outbreaks are variable and can range in intensity, including feelings of anxiety, a sense of shame, failure or weakness of the individual and society; an underestimation of likelihood of survival; an overestimation of likelihood of infection [1]; an urge to take flight from the outbreak; excessive, inappropriate adoption of precautionary measures; and increased demand for healthcare services during a critical shortage [2].
Widespread outbreaks of infectious disease, such as COVID-19, are associated with psychological distress and symptoms of mental illness [3]. With the global development of the coronavirus disease (COVID-19) outbreak, the psychological issues which accompany this pandemic have rapidly compounded its public health burden [4]. Emerging research assessing the mental health implications of COVID-19 has identified a heightened prevalence of moderate-tosevere self-reported depressive and anxious symptomatology among the general public [5]. Psychiatrists across the world should be aware of these manifestations, their correlates, and strategies to manage them that encompass both the needs of specific populations [6] and the precautionary measures necessary to contain the spread of COVID-19 [6]. Many studies have demonstrated the impact of infectious disease outbreaks on public mental health. These types of epidemics lead the public to experience psychological problems such as post-traumatic stress disorder, psychological distress, depression and anxiety [7]. Some studies have shown that post-traumatic stress disorder is closely related to depression and other psychological problems [8]. 
Negative mental health effects due to social isolation may be particularly pronounced among older adults and households with adolescents, as these groups are already at risk for depression or suicidal ideation. It is well known that the students experience lots of stress especially before and during the examinations. As the examinations were postponed due to the lockdown effect and many under-graduate college students are in dilemma whether there will be any examination or they have to make them ready for the next semester syllabus. In this context many students were undergoing mental stress and there is a strong need to consider their mental health status. For college students, heightened levels of psychological distress and downstream negative academic consequences are prevalent under normal circumstances [9]. As a result of physical distancing measures implemented in response to COVID-19, tertiary education institutions have shifted to an emergency online learning format, which would be expected to further exacerbate academic stressors for students. To date, one published study has explored the impact of COVID-19 on student education and wellbeing [10]. Approximately $25 \%$ of their sample reported experiencing anxiety symptoms, which were positively correlated with increased concerns about academic delays, economic effects of the pandemic, and impacts on daily life [11].

Depression for college students covers several domains of effective functioning and can lead to significant negative outcomes both academically and psychologically. Students with depressive symptoms may experience difficulty sleeping, changes in weight, and an increased likelihood of suicidal thoughts in addition to problems with academic learning [12]. The pandemic is occurring against the backdrop of increased prevalence of mental health issues in the UK in recent years in some groups $[13,14]$. The general population survey, done by Ipsos MORI [15] revealed widespread concerns about the effect of social isolation or social distancing on wellbeing; increased anxiety, depression, stress, and other negative feelings. Many universities decided to suspend in-person classes and evacuate students in responding to the intensifying concerns surrounding COVID-19. This action can lead to negative psychological consequences among college students. College students often experience compounded negative emotions during the school "closure" [16]. Some may struggle with loneliness and isolation while sheltering in place because of disconnections from friends and partners. College students experience distress contributed by the uncertainty and abrupt disruption of the semester in addition to the anxiety caused by school closure.

Prolong lockdown and social isolation used by different countries to control the COVID-19 pandemic is expected to cause even more depressions and mental health problems even during unlock phase of COVID19 lockdown. In addition, social isolation, even removed from the sudden enforced isolation resulting from COVID-19 lockdowns, can lead to increased cases of depression, psychosis, delusions and suicidal behaviour. In addition, social isolation, even removed from the sudden enforced isolation resulting from COVID-19 lockdowns, can lead to increased cases of psychosis, delusions, and suicidal behaviour, as well as higher numbers of hospitalizations [17]. Research shows that feelings of helplessness, loneliness and fear of being socially excluded, stigmatized or separated from loved ones are common in any epidemic, while prolonged stress, boredom and social isolation, as well as a lack of outdoor play, can lead to a higher number of mental health conditions in children, such as anxiety and even depression [17]. Prolonged social isolation our primary strategy to reduce the spread of the virus adds another layer of risk. Our bodies are not designed to handle social deprivation for long. Past studies suggest that people forced to "shelter in place" will experience more depression. Those living alone and lacking social opportunities are at risk. Loneliness breeds depression. Families, who must navigate unusual amounts of time together in confined spaces, may experience more conflict, also increasing risk [18]. In addition, patients with a history of psychiatric illnesses and who were isolated had a high risk of anxiety and anger at 4-6 months after withdrawal from isolation due to lockdown.

Social support has been described as "support accessible to an individual through social ties to other individuals, groups, and the larger community" [19]. It can be defined terms of social network characteristicssuch as assistance from family, friends, neighbours, and other community members-that help individuals to cope with everyday life, particularly in response to critical situations $[20,21]$. Perceived support seems to be most important (), especially when stress is experienced [22]. Several researchers identified the positive role that social support plays in buffering the stress inherent in being a college student [23, 11]. Social support has been positively linked with better health, productive personal relationships, and academic achievement [24]. Students who perceive they have social supports are less likely to experience academic stress and more likely to successfully navigate college life, persist, and achieve their academic goals [23, 11]. During times of stress, college students may seek social support from family, friends, classmates, and faculty, and research has shown that perceived social support buffers the deleterious effects of stress. Since Durkheim first established that social support has a positive effect on health [25], many researchers have found that this support can serve as a mediator between stress and psychological problems [26].

The Government of West Bengal announced a complete lockdown in West Bengal on March 22 to impose a complete safety restriction due to COVID-19. On March 23, Prime Minister of India, Mr. Narendra 
Modi announced a nationwide lockdown (India Times. 18 March 2020). The COVID-19 pandemic was first confirmed in Kolkata, capital of West Bengal on 17 March 2020 in Kolkata (The Economic Times, 29th April, 2020). Union home ministry releasing details of the first of a three-phase plan aimed at lifting stringent restrictions imposed over two months ago to stop the spread of the coronavirus disease (Covid-19) from $8^{\text {th }}$ June. The plan, called Unlock 1.0, also removes restrictions on inter- and intra-state travel. After spending almost a fifth of the year (68 days) locked down, Indians can resume normal activities againalbeit with significant safeguards (Hindustan Times, $31^{\text {st }}$ May, 2020). New guidelines announced by the Centre for Unlock 2.0 starting July 1 said training institutes run by the central and state governments will be allowed to function from the middle of July while schools and colleges will remain closed (Times of India, 1st July, 2020).

Data were collected during this unlock phaseII when colleges were closed and students were forced to stay at home.

Considering the above, the present investigation had the following aims and objectives on the basis of certain selected variables- perceived interpersonal support evaluation \& perceived depression experienced during unlocking phase of Covid-19 lockdown:

1. To study the significant difference, if any, between male and female undergraduate college students residing in Kolkata on perceived interpersonal support evaluation during unlock phase of Covid-19 lockdown.

2. To study the differential effects, if any, in depression as experienced by male and female undergraduate college students of Kolkata during unlock phase of Covid-19 lockdown.

3. To explore, if any, the correlation between interpersonal support evaluation and depression experienced during this turmoil phase for both sexes, separately during unlock phase.

\section{HYPOTHESES}

I. Male undergraduate college students living in Kolkata will significantly differ from their female counterparts in respect of their perceived interpersonal support evaluation, viz. Appraisal Support, Belonging Support and Tangible Support.

II. Male undergraduate college students will be significantly different from female group in respect of their depression as experienced during unlock phase of Covid-19 lockdown.

III. The psychological variables of the study, viz. perceived interpersonal support evaluation (including its three factors- appraisal support, belonging support and tangible support) \& depression would correlate significantly with each other for male \& female group separately.

\section{EXPerimental Section Participants}

A Web-based survey composed of a group of 200 Undergraduate college students (100 males and 100 females) residing in Kolkata had been done during unlock phase - II of Covid-19 lockdown. Participants belonging to 18 to 20 years old were considered for the present study. All were undergraduate college students and their family structures were nuclear type. Their monthly family income ranged from Rs. 30,000/- to 50,000/-. Subjects with chronic physical and mental disorder were excluded by suitable screening through questions asked in general information schedule.

\section{Survey Instruments}

General Information Schedule: It elicits information about socio-demographic variables like age, sex, education, domicile, family structure and family income etc.

\section{The Beck Depression Inventory - Second Edition (BDI-II)}

BDI-II is a 21-item, self-rated scale that evaluates key symptoms of depression including mood, pessimism, sense of failure, self-dissatisfaction, guilt, punishment, self-dislike, self-accusation, suicidal ideas, crying, irritability, social withdrawal, indecisiveness, body image change, work difficulty, insomnia, fatigability, loss of appetite, weight loss, somatic preoccupation, and loss of libido [27]. It is designed to measure severity of depression consistent with symptoms of depression as presented in the Diagnostic and Statistical Manual of Mental Disorders - Fourth Edition [9] in both adolescents aged 13 years and older and adults [27]. Construct validity is high for the medical symptoms measured by the questionnaire, $\alpha=0.92$ for psychiatric outpatients and 0.93 for college students [27]. The BDI-II positively correlated with the Hamilton Depression Rating Scale, $r=0.71$, had a oneweek test-retest reliability of $r=0.93$ and an internal consistency $\alpha=.91$.

\section{Interpersonal Support Evaluation List (shortened version)}

Interpersonal Support Evaluation List (shortened version) is a 12-item measure of perceptions of social support. This measure is a shortened version of the original ISEL (40 items; Cohen \& Hoberman [28]. This questionnaire has three different subscales designed to measure three dimensions of perceived social support. These dimensions are Appraisal Support, Belonging Support and Tangible Support. Each dimension is measured by 4 items on a 4-point scale ranging from "Definitely True" to "Definitely False". All items are summed to yield a total score (scores 
range 0-36) and three domains comprised of four items each. ISEL-12 scores correlated positively with network integration and life engagement, and inversely with stress, anxiety, and depression. All correlations were moderate in magnitude.

\section{Collection of Data}

Data were collected through web-based survey method from the undergraduate college students of Kolkata city during unlock phase-II of COVID-19 lockdown. Both male and female college students were approached online through mail and social networking sites. All the interested participants were provided online questionnaires through mails.

\section{RESUltS AND DisCUSSION}

Table-1: Descriptive Statistics and Mean Differences with respect to Study Variables

\begin{tabular}{|c|c|c|c|c|c|c|c|}
\hline \multirow[t]{2}{*}{ Variables } & \multicolumn{2}{|c|}{ Total $(N=200)$} & \multicolumn{2}{|c|}{ Male $(\mathrm{N}=100)$} & \multicolumn{2}{|c|}{ Female $(\mathbf{N}=100)$} & \multirow[t]{2}{*}{$t$ value } \\
\hline & Mean & SD & Mean & SD & Mean & SD & \\
\hline SS_TOT & 25.31 & 6.885 & 28.38 & 6.15 & 22.23 & 6.20 & $7.05 * *$ \\
\hline$\overline{\mathrm{ASS}}$ & 7.89 & 2.71 & 8.56 & 2.30 & 7.21 & 2.91 & $3.64 * *$ \\
\hline BSS & 8.95 & 2.74 & 10.53 & 1.75 & 7.37 & 2.64 & $9.98 * *$ \\
\hline TSS & 8.47 & 2.51 & 9.29 & 2.18 & 7.65 & 2.57 & $4.87 * *$ \\
\hline BD_II & 17.75 & 11.62 & 14.89 & 10.84 & 20.61 & 11.72 & $-3.58 * *$ \\
\hline
\end{tabular}

Above table presents the descriptive results of the students for different groups. Mean and standard deviation (SD) were done to know the average score and variance of the students on the particular variables and $t$ tests were done to see the significant difference between male and female students for social support and depression. It was found that the total social support for the male students was significantly higher than the female students $\left(\mathrm{t}_{[198]}=7.05, \mathrm{p}<0.01\right)$ including its dimensions Appraisal Support subscale (ASS) $\left(\mathrm{t}_{[198]}=\right.$ 3.64, $\mathrm{p}<0.01$ ), Belonging Support subscale (BSS) $\left(\mathrm{t}_{[198]}\right.$ $=9.98, \mathrm{p}<0.01)$, and Tangible Support subscale $(\mathrm{TSS})(\mathrm{t}$ $\left.{ }_{[198]}=4.87, \mathrm{p}<0.01\right)$. Female college students lack social support in comparison to male students. It can also be said that there is a significant difference in the overall perception of social support among male and female college students. Interpersonal social support of boys was higher than girls. This can be attributed to the gender differences in socialization and social roles, as established by literature [29].

Female students scored higher in BDI - II also than male students $\left(\mathrm{t}_{[198]}=3.58, \mathrm{p}<0.01\right)$. It may be due to girls are expected to be more emotionally sensitive [30], suffer more from stressors which involve significant others such as the death of friends or relatives [31] which is especially true during this present COVID scenario, experience more restricted gender roles $[32,33]$, experience more family violence, abuse in home environment $[34,35]$ and may become vulnerable in confinement due to lockdown, which all have been associated with a greater likelihood of greater depression among girls than boys.

The findings support H-I which states male undergraduate college students living in Kolkata are significantly differ from their female counterparts in respect of their perceived interpersonal support evaluation, viz. Appraisal Support, Belonging Support and Tangible Support.

The findings support $\mathrm{H}$-II which states male undergraduate college students are significantly different from female group in respect of their depression as experienced during unlock phase of Covid-19 lockdown.

Table-2: Correlation Coefficients between Social Support and Depression
\begin{tabular}{|c|c|c|c|}
\hline \multirow{2}{*}{ Variables } & \multicolumn{3}{|c|}{ BD_II } \\
\cline { 2 - 4 } & Total & Male & Female \\
\hline SS_TOT & $-.677 * *$ & $-.92^{* *}$ & $-.41^{* *}$ \\
\hline ASS & $-.590^{* *}$ & $-.92^{* *}$ & $-.31^{* *}$ \\
\hline BSS & $-.519 * *$ & $-.90^{* *}$ & $-.23 *$ \\
\hline TSS & $-.654^{* *}$ & $-.90^{* *}$ & $-.42^{* *}$ \\
\hline
\end{tabular}
$* *$ Correlation is significant at the 0.01 level.
* Correlation is significant at the 0.05 level.

From the above table Social support and its dimensions were found to be significantly and negatively correlated with depression for all groups. It implies that higher the social support students get less they have depression which may be due to social causation model assumes that social support is an antecedent of well-being, and lack of social support causes psychological distress. Such results are 
consistent with the finding of Kaniasty and Norris, [36]. People will have depression when they lack of social support, and when depressed, people are less prone to obtain or sustain relationships. Social support was considered to be protective against depression and there was a negative spiral between social support and depression. This finding is also confirmed by the study of Cooley and associates [37].

The findings support H- III which states social support significantly correlated depression of the college students.

\begin{tabular}{|c|c|c|c|c|}
\hline \multirow[t]{2}{*}{ Model } & & \multirow[t]{2}{*}{$\mathbf{R}^{2}$} & $\begin{array}{l}\text { Standardized } \\
\text { Coefficients }\end{array}$ & \multirow[t]{2}{*}{$\mathbf{t}$} \\
\hline & & & Beta & \\
\hline \multirow[t]{2}{*}{1} & (Constant) & \multirow[t]{2}{*}{.46} & & $20.159 * *$ \\
\hline & SS_TOT & & -.677 & $-12.941 * *$ \\
\hline \multirow[t]{3}{*}{2} & (Constant) & \multirow[t]{3}{*}{.48} & & $20.564 * *$ \\
\hline & SS_TOT & & -.446 & $-4.221 * *$ \\
\hline & $\overline{\text { TSS }}$ & & -.264 & $-2.499 * *$ \\
\hline
\end{tabular}

Stepwise regression was done to see the significant prediction of depression for total sample. It showed that total. The proportion of the variance of depression explained by this model is $48 \%\left(\mathrm{R}^{2}\right.$ for final model). From beta coefficients it is found that total social support score and tangible support subscale significantly predicted depression by 0.446 and 0.264 (the coefficient is negative) respectively in the students. Judging by this result, it can be said that students are less depressed when they get more social support and especially the tangible support. It may be due to Social ties have a beneficial influence on the maintenance of psychological well-being and health-promoting behaviour and consistent with the research of Kawaci [38]. Social support involves interaction between the individual and the social network such that tangible and intangible benefits are exchanged. Being able to turn to others for support may mitigate the effects of pain and functional impairment and attenuate the psychological distress associated with them and this also get its support from the work of Lambert [39], Alloway \& Bebbington [40]. Social support attenuates the adverse effects of stressors such as pain and functional limitations on well-being. Persons with strong social support are better able to cope with stressors, whereas those with less support may be more vulnerable to the adverse effects of stress, such as depression which can be supported by the study of Revicki [41] and Roberts et al., [42]. Greater social support has been associated with lower depression [43, 44]. Further, tangible social support is the most probable aspect of social support that can buffer the effects of stressful situations and that can also be supported by the study of Cohen [45]. Tangible support is based on practical support, such as material aid and behavioural assistance [46], therefore proved to be more effective form of social support for adolescents.

The findings support H- IV which states social support significantly predicts depression of the college students. Social support and its dimensions were found to be significantly and negatively correlated with depression for all groups which implies that higher the social support students get, less they have depression.

\section{CONCLUSION}

It was found that the female college students scored higher in depression than male students and in case of social support female college students scored comparatively less than male students during unlock phase II for Covid-19 pandemic. Social support can be considered to be protective force against depression and there was a negative spiral between social support and depression. Results also confirmed that students are less depressed when they get more social support and especially the tangible support. Persons with strong social support are better able to cope with stressors, whereas those with less support may be more vulnerable to the adverse effects of stress, such as depression.

\section{REFERENCES}

1. Koh, D. (2005). Risk Perception and Impact of Severe Acute Respiratory Syndrome (SARS) on Work and Personal Lives of Healthcare Workers in Singapore What Can We Learn? Medical Care, 43(7), 676-682.

2. Rosling, L. \& Rosling, M. (2003). Pneumonia causes panic in Guangdong province. $B M J$, 326(7386): 416.

3. Bao, Y., Sun, Y., Meng, S., Shi, J., \& Lu, L. (2020). 2019-nCoV epidemic: address mental health care to empower society. Lancet, 395(10224):e37-e38, 02-22.

4. Torales, J., O’Higgins, M., Castaldelli-Maia, J. M., $\&$ Ventriglio, A. (2020). The outbreak of COVID19 coronavirus and its impact on global mental health. International Journal of Social Psychiatry, 66(4), 317-320.

5. Wang, J., Lloyd-Evans, B., \& Giacco, D. (2017). Social isolation in mental health: A conceptual and methodological review. Social Psychiatry of Epidemiology. 52(12), 14-51. 
6. Liu, S., Yang, L., Zhang, C., Xiang, Y. T., Liu, Z. $\& \mathrm{Hu}$, S. (2020). Online mental health services in China during the COVID-19 outbreak. Lancet Psychiatry, 7(4), e17-e18.

7. Shultz, J. M., Baingana, F., \& Neria, Y. (2015). The 2014 Ebola outbreak and mental health: current status and recommended response. JAMA, 313, 567-568.

8. Qu, Z., Wang, C. W., Zhang, X., Ho, A. H., \& Wang, X. (2014). Prevalence and determinants of depression among survivors 8 months after the Wenchuan earthquake. J Nerv Ment Dis. 202, 275279.

9. American College Health Association. (2019). American College Health Association: National College health assessment II: Reference group executive summary spring 2019. American College Health Association.

10. Cao, W., Fang, Z., Hou, G., Han, M., Xu, X., Dong, J., \& Zheng, J. (2020). The psychological impact of the COVID-19 epidemic on college students in China. Psychiatry Research, 287, Article 112984.

11. Skowron, E. A., Wester, S. R., \& Azen, R. (2004). Differentiation of self-mediates college stress and adjustment. Journal of Counselling \& Development, 82(1), 69-78.

12. American Psychiatric Association. (2000). Diagnostic and Statistical Manual of Mental Disorders. 4th edn. Washington, DC: American Psychiatric Association.

13. McManus, S., Hassiotis, A., Jenkins, R., Dennis, M., Aznar, C. \& Appleby, L. (2016). Suicidal thoughts, suicide attempts and self-harm. In S. McManus, P. Bebbington, R. Jenkins., \& $\mathrm{T}$. Brugha, (Eds.). Mental health and wellbeing in England: Adult Psychiatric Morbidity Survey 2014. Leeds: NHS Digital.

14. Ford, T., Vizard, T., \& Sadler, K., (2020). Data resource profile: the mental health of children and young people surveys (MHCYP). International Journal of Epidemiology.

15. The Academy of Medical Sciences 2020. http://www.acmedsci.ac.uk/COVIDmentalhealthsur veys

16. Van Bortel T., Basnayake A., Wurie F., Jambai M., Koroma A.S., Muana A.T., Hann K., Eaton J., Martin, S., \& Nellums L.B. (2016). Psychosocial effects of an Ebola outbreak at individual, community and international levels. Bull. World Health Organ. doi: 10.2471/blt.15.158543.

17. Wang, C., Horby, P. W., Hayden, F. G. \& Gao, G. F. (2020). A novel coronavirus outbreak of global health concern. Lancet, 395, 470-473.

18. Maxime, T., Jordi, Q., James, J., Gross, K. E., Saunders, G. M. \& Goodwin. (2020). Mood Homeostasis, Low Mood, and History of Depression in 2 Large Population Samples. JAMA Psychiatry, 22; e200588.
19. Lin, N., Simeone, R. S., Ensel, W. M., \& Kuo, W. (1979). Social support, stressful life events, and illness: A model and an empirical test. Journal of Health Social Behaviour, 20, 108-119.

20. Pierce, G. R., Sarason, B. R., \& Sarason, I. G. (1990) Integrating social support perspectives: Working models, personal relationships and situational factors. In S. Duck, (Ed.). Personal relationships and social support, (pp. 173-215). London: Sage Publications.

21. Helgeson, V. S. (2003). Gender-related traits and health. In J. Suls, \& K. A. Wallston (Eds.), Blackwell series in health psychology and behavioural medicine: Social psychological foundations of health and illness (pp. 367-394). Blackwell Publishing.

22. Zhou, E. S., Penedo, F. J., Lewis, J. E., Rasheed, M., Traeger, L., \& Lechner, S. (2010). Perceived stress mediates the effects of social support on health-related quality of life among men treated for localized prostate cancer. J. Psychosom Res. 69, 587-590. doi: 10.1016/j.jpsychores.2010.04.019

23. Baldwin, D. R., Chambliss, L. N., \& Towler, K. (2003). Optimism and stress: An African-American college student perspective. College Student Journal, 36, 278-285.

24. Goldsmith, D. J. (2004). Communicating social support. New York, NY: Cambridge.

25. Berkman, L. F., Glass, T., Brissette, I., \& Seeman, T. E. (2000). From social integration to health: Durkheim in the new millennium. Social Science and Medicine, 51(6), 843-857.

26. Lancaster, C. A. (2010). Risk factors for depressive symptoms during pregnancy: a systematic review. American Journal of Obstetrics and Gynecology, 202(1), 5-14.

27. Beck, A. T., Steer, R. A. (1987). Manual for the Beck Depression Inventory. San Antonio, TX: The Psychological Corporation.

28. Cohen, S, Mermelstein, R., Kamarck, T. \& Hoberman, H. M. (1985). Measuring the functional components of social support. In I. G. Sarason, B. R. Sarason, (Eds.), Social support: theory, research, and applications, (pp. 73-94). Martinus Nijhoff: The Hague, Holland.

29. Tanwar, R. (2013). Porter's generic competitive strategies. Journal of business and management, 15(1), 11-17.

30. Rosenfield, S., \& Mouzon, D. (2013). Gender and mental health. In: Aneshensel CS, Phelan JC, Bierman A, editors. Handbook of the sociology of mental health: Springer Netherlands, p. 277-296.

31. Matud, M. P. (2004). Gender differences in stress and coping styles. Personal Individ Differ, 37, 1401-1415.

32. Rodríguez-Cano, T., Beato-Fernández, L. \& Llario, A. B. (2006). Body dissatisfaction as a predictor of self-reported suicide attempts in adolescents: a Spanish community prospective study. J Adolesc Health. 38, 684-698. 
33. Haugen, T., Johansen, B. T. \& Ommundsen, Y. (2014). The role of gender in the relationship between physical activity, appearance evaluation and psychological distress. Child Adolesc Ment Health, 19, 24-30.

34. Elliott, M. (2001). Gender differences in causes of depression. Women Health, 33, 163-177.

35. Wiklund, M., Malmgren-Olsson, E. B., Öhman, A., Bergström, E. \& Fjellman-Wiklund, A. (2012). Subjective health complaints in older adolescents are related to perceived stress, anxiety and gender a cross-sectional school study in northern Sweden. BMC Public Health, 12, 993-1009.

36. Kaniasty, K., \& Norris, F. H. (2008). Longitudinal linkages between perceived social support and posttraumatic stress symptoms: sequential roles of social causation and social selection. J. Trauma Stress, 21, 274-281.

37. Cooley, E. L., Van-Buren, A. \& Cole, S. P. (2010). Attachment styles, social skills, and depression in college women. J. College Couns, 13, 50-62.

38. Kawachi, I., \& Berkman, L. F. (2001). Social ties and mental health. Journal of Urban Health, 78(3), 458-467.

39. Lambert, V. A. (1985). Study of factors associated with psychological well-being in rheumatoid arthritis women. Image J Nurs Sch, 17, 50-53.
40. Alloway, R., Bebbington, P. (1987). The buffer theory of social support-a review of the literature. Psychol Med, 17, 91- 108.

41. Revicki, D. A., \& Mitchell, J. P. (1990). Strain, social support, and mental health in rural elderly individuals. J. Gerontol, 920-925.

42. Roberts, B. L., Dunkle, R. \& Haug, M. (1994). Physical, psychological and social resources as moderators of the relationship of stress to depression and general mental health. J Gerontl, 49, 35-43.

43. Godding, P. R., McAnulty, R. D., Wittrock, D. A., Britt, D. M., \& Khansur, T. P. (1995). Predictors of depression among male cancer patients. J Nerv Ment Dis, 183, 95-98.

44. Sequin, L., Potvin, L., Denis, M., \& Loiselle, J. (1995). Chronic stressors, social support, and depression during pregnancy. Obstet Gynecol, 85, 583-589.

45. Cohen, S., \& Wills, T. A. (1985). Stress, social support, and the buffering hypothesis. Psychol Bull, 98(2), 310-357.

46. Sherbourne, C. D., \& Stewart, A. L. (1991). The MOS social support survey. Social Science \& Medicine, 32(6), 705-714. 